\title{
Lack of congruence between morphometric evolution and genetic differentiation suggests a recent dispersal and local habitat adaptation of the Madeiran lizard Lacerta dugesii
}

\author{
António BReHM ${ }^{\mathrm{a}, *}$, Mahnaz KHAdEM ${ }^{\mathrm{b}}$, \\ José Jesus ${ }^{\mathrm{a}}$, Paula ANDRADE ${ }^{\mathrm{b}}$, Luis VICENTE ${ }^{\mathrm{c}}$ \\ ${ }^{a}$ Centre of Biological and Geological Sciences, \\ Campus of Penteada, 9000 Funchal, Portugal \\ ${ }^{\mathrm{b}}$ Department of Biology, University of Madeira, 9000 Funchal, Portugal \\ ${ }^{c}$ Centre of Environmental Biology, Departments of Zoology and Anthropology, \\ Science Faculty of Lisbon, \\ University of Lisbon, C2 Campo Grande, 1700 Lisbon, Portugal
}

(Received 22 March 2000; accepted 6 July 2001)

\begin{abstract}
Genetic differentiation among nine populations of the endemic lizard Lacerta dugesii Milne-Edwards 1829 (Lacertidae) from four groups of islands constituting the Archipelago of Madeira, was investigated by protein electrophoresis at 23 enzyme loci. Among twenty polymorphic loci, the total genetic diversity was due primarily to intra-population variation. The allele and genotypic frequencies among populations showed some heterogeneity, allowing the species to present a structuring pattern compatible with their geographical clustering. Some evidence suggests that selection acting on some loci in different ecological conditions may be responsible for the clustering of the populations studied. There was no apparent isolation effect expected under an "island" model of population divergence, and no correlation was found between genetic and geographic distances among populations. Morphological variation of the proposed three $L$. dugesii subspecies is not congruent with the allozyme analysis. This most probably suggests a rapid colonization of the islands followed by a strong effect of selection operating over the morphological characters used to define the subspecies.
\end{abstract}

Lacerta dugesii / allozymes / morphology / geographical population structure

* Correspondence and reprints

E-mail: brehm@uma.pt 


\section{INTRODUCTION}

Islands constitute excellent systems for studying divergence and speciation in lizard populations because in most cases gene flow is almost completely absent and each island becomes a discrete unit [15]. Patterns of genetic variation among islands can thus be attributed to population history, founder events, drift or selection. Divergence may be a direct consequence of geographic distance separating the populations (isolation-by-distance model [35]), although selection may contribute to this divergence when populations are under different ecological conditions [30]. All these processes may produce similar patterns of population genetic structuring making it difficult to distinguish these alternative hypotheses. It has recently been shown [19] that rapid adaptative radiation of lizards in similar environments could overcome historical contingencies, producing morphological similar outcomes on genetically different individuals. Natural selection acting in similar habitats can be the major force in generating phenotypic (and thus morphological) diversity in lizards [19].

The Madeira Archipelago consists of Madeira and Porto Santo Islands plus two groups of smaller islands (Selvagens and Desertas). Distances between the islands vary from a few kilometres to $300 \mathrm{~km}$ (Fig. 1). Madeira is the largest island and has a climate ranging from humid subtropical in the north to hot and arid in the south and east. Porto Santo, Desertas, and Selvagens are arid, with sparse vegetation. Except the presence of the gecko Tarentola bischoffi in the Selvagens, Lacerta dugesii is the sole flightless vertebrate endemic to the Archipelago. Its origin, (European or African) and the time and historical colonization of the islands are unknown. The species does not have any close relative in the Canary Islands, although this archipelago is close to the Selvagens. According to morphological and molecular data, the sister species of Lacerta dugesii is L. perspicillata, endemic to Morocco [17]. Lacerta dugesii is a small lizard that shows considerable color and pattern variability among populations $[2,3,9,10]$. Its phenotypic variation remains to be understood but could be the result of selection over different habitats in Anolis and Tropidurus $[19,23,32]$. The species is extremely abundant, occurring on all islands of the archipelago, and occupying habitats ranging from sea level to the highest point (1 800 meters) of Madeira. Lacerta dugesii is omnivorous and its only natural predators are birds of prey and rats. Its taxonomic status remains under discussion but here we have adopted the name Lacerta dugesii following Arnold [1]. The species has been seen aboard the ships that occasionally link Madeira Island with the Desertas and Selvagens groups (pers. obs.). The heavy maritime traffic existing between the two inhabited islands (Madeira and Porto Santo) makes the exchange of individuals between them extremely plausible. Few studies have investigated intra-specific divergence of $L$. dugesii. Morphological variation of the individuals on Madeira Island or among the four 


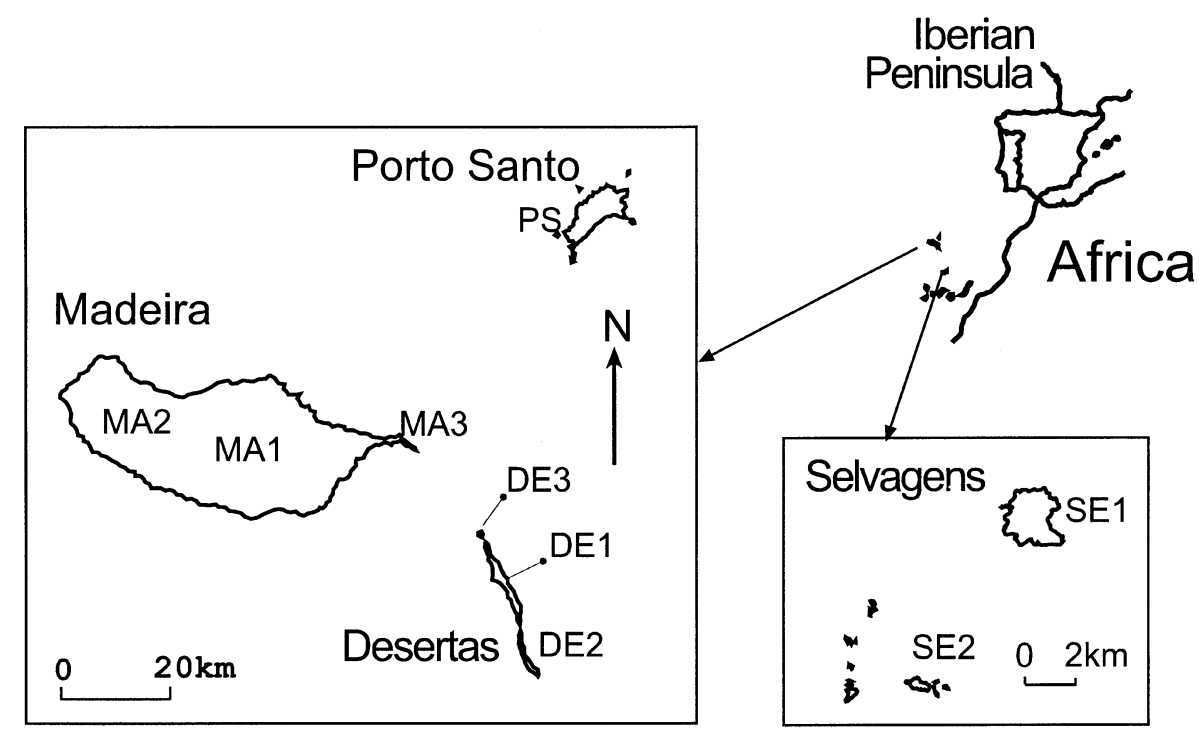

Figure 1. Map of the Archipelago of Madeira, showing the location of population samples used in this work. Codes of populations are as follows: Madeira group of islands (MA1, MA2, MA3), Desertas group of islands (DE1, DE2, DE3), Porto Santo Island (PS), and the Selvagens group of islands (SE1, SE2).

groups of islands has been addressed [2,9]. Bischoff et al. [4] have presented both morphological and allozyme data but the number of specimens studied was relatively small ( 175 for the morphological characters, but only 22 individuals from five islands were assayed for allozyme characters). A dendrogram based on these data was consistent with the biogeographical distribution of $L$. dugesii populations. Based on these studies, Bischoff et al. [4] proposed the existence of three subspecies: Podarcis dugesii dugesii (Desertas Islands), P. dugesii jogeri (Porto Santo Island) and P. dugesii selvagensis (Selvagens Islands) [4]. The population from Madeira was given no subspecific name.

In the present study, we examined allozyme variation within and among nine populations distributed across the archipelago in order to look for any pattern of genetic structure. The results revealed a rather weak pattern of genetic differentiation in the populations of $L$. dugesii congruent with their geographic distribution. The habitat shift prevailing in the different populations could favor selection to act differently upon certain loci and therefore be responsible for the pattern observed. A comparison of our results with those of Bischoff et al. [4] inferred from morphological characters revealed a total lack of congruence between the two types of data. Multidimensional analysis of genetic distances based on these two types of data showed different geographic clustering of the populations, a fact that may be due to a recent divergence 
of populations, subjected to differential selective constraints and adapted to different habitats.

\section{MATERIALS AND METHODS}

\subsection{Samples and gel electrophoresis}

Specimens of $L$. dugesii were collected from nine locations, spanning the Madeira Archipelago (Fig. 1). Liver tissue was removed from 410 specimens and frozen at $-70^{\circ} \mathrm{C}$. The tissues were homogenized in an equal volume of distilled water, followed by centrifugation at $10000 \mathrm{~g}$ for $30 \mathrm{~min}$ at $4{ }^{\circ} \mathrm{C}$. Supernatants were collected and stored at $-20^{\circ} \mathrm{C}$. Protocols for horizontal starch gel electrophoresis and histochemical staining were similar to those described previously [21]. Samples from two individuals of known electrophoretic mobility for a given locus were used in each gel as markers. Enzyme systems are listed in the Appendix and buffer systems are available from the authors upon request.

\subsection{Analysis of genetic diversity}

Allele frequencies and measures of intra- and inter-population variation (average heterozygosity, percent polymorphic loci, mean number of alleles per locus, within and overall gene diversity) were estimated with GENEPOPv3.1d [24]. Gene diversity parameters include within and overall gene diversity ( $H s$ and $H t$ ), and Nei [22] GST and GIS as measures of gene diversity among populations [22,24,33,34]. Exact tests for divergence from Hardy-Weinberg Equilibrium (HWE) were done for each locus in each population with $P$-values estimated by the Markov chain method [16]. Population differentiation at each locus and over all loci among populations, was tested by estimating unbiased $P$-values of a $\log$-likelihood $G$-exact test, using FSTAT [13]. Random permutation procedures were used to test whether values differed significantly from zero. The amount of gene flow among populations was estimated within each island by substituting FST with GST in Wright's [34] island model of gene flow. This model estimates $N m=(1-G S T) / 2 G S T_{\alpha}$ with $N m$ being the effective number of migrants per generation, and $\alpha=(n /(n-1)) 2$, where $n$ is the number of populations. An AMOVA [12] on genotype frequencies in each population was performed with the software ARLEQUIN [27], to test the hierarchical partitioning of genetic variability within and among populations of the four groups of islands. Significance of $F S T$ values was assessed by random permutation tests. Pairwise Cavalli-Sforza and Edwards [6] chord distance was calculated and subjected to Multidimensional Scaling (MDS) [18] using NTSYS-pc [26]. Correlation between genetic and geographic distances among populations was tested with 
Option 6 of GENEPOPv3.1d [24], based on Slatkin and Maddison's [29] isolation by distance model, using $F$ instead of $F S T$ [8]. Finally we performed an MDS plot using the mean values of morphometric characters (meristics and pholidotics) of individuals belonging to six populations of $L$. dugesii published by Bischoff $e t$ al. [4]. The values were first standardized and a distance matrix was constructed based on Euclidean distances. Whenever possible we kept the same population codes to allow an easier comparison.

\section{RESULTS}

Twenty-three presumptive loci were scored for all populations (see Appendix); three of these (AK, PGI and SOD) were monomorphic and were excluded from data analysis. Mean number of alleles per locus was similar across populations, varying from 1.7 to 2.1 . Direct-count heterozygosity estimates $(\mathrm{H})$ ranged from 0.10 to 0.22 . The percentage of polymorphic loci (presence of more than one allele) varied from 55\% to 85\% (see Appendix). Heterozygosity among populations did not differ significantly (two way ANOVA, $F=1.68$, NS), and island size and mean heterozygosity were not related $(F=0.34$, NS). There were no fixed differences between populations at any locus. Some alleles were archipelago-specific: G3PDH-allele 3, AAT-allele 3 and G6PDH-allele 3 from the Selvagens Islands (SE1, SE2), Est-allele 4 and LDH2-allele 3 from the Desertas Islands (DE2, DE3), MDH-alleles 5,6, PEP1allele 4 and PEP3-allele 4, which are specific to the Porto Santo Island (PS). Most of the populations showed a high percentage of loci in which the most common allele was at a frequency greater than $90 \%$. Only 16 out of 106 tests for conformity to HWE in individual loci in each population, showed a significant deficit of heterozygotes when $\alpha$ was set to 0.005 (data not shown). Pooling the genotypes into three classes: (1) homozygotes for the most common allele, (2) common and rare heterozygotes and (3) rare homozygotes, thereby avoiding classes with an expected low allele frequency, did not change the results. Table I gives basic genetic diversity measures, $P$-values associated to Hardy-Weinberg expectations for each locus across all populations, and probability exact tests related to genotypic differentiation across all populations. All $P$-values were subjected to Bonferroni corrections, and $\alpha$ was set to 0.002 since 20 tests were done $(0.05: 20)$. Even so, seven loci showed deviation to HWE, all in the direction of heterozygote deficiency. Except for ME-1, PEP-2, G6PDH, LDH-1, PGM-2 and XDH, genotypic distributions differed significantly $(P<0.0001)$ across populations (Tab. I). We followed Nei [22] notation and measured genetic differentiation among populations as GIS and GST. The mean values of GIS and GST for all populations across all loci surveyed were 0.27 and 0.19 respectively. Unbiased estimates of $\log$-likelihood $(G)$-based exact tests for population differentiation revealed significant genotypic differences among all 
populations, indicating a major pattern of heterogeneity among loci (Tab. I). The same tests done between pairs of populations belonging to the four groups of islands either within or among these groups gave similar results (data not shown). The highest number of loci with significant $P$-values of genotypic differentiation tests (in all cases $P<0.05, \alpha=0.002$ ) was found between population pairs MA1-MA2 and MA2-MA3 from Madeira Island (nine and five loci respectively). Also, two populations of the Desertas group (DE2 and DE3) showed seven loci with significant $P$-values. Pooling the populations from the same group, and applying the same tests, led us to uncover some loci such as EST, MDH and PEP-3, which consistently showed strong genotypic structure among these groups. Other loci discriminate a particular group of populations (AAT, G6PDH, ME-3 in Selvagens, or LAP and PEP-3 Porto Santo island, data not shown). Three loci (PGM-2, XDH, MPI) did not show any significant $P$-values related to genotypic differentiation either within or among groups. Pooling the populations from each of the three archipelagos (Madeira, Desertas and Selvagens) allowed us to compare the respective GSTand $G I S$-values (Tab. II). The three populations from Madeira Island showed the highest genotype heterogeneity. The GST-values depicted in Table II also clearly indicate that the two populations from Selvagens were the least differentiated.

The AMOVA results are shown in Table III and indicate that $99.7 \%$ of the genetic differentiation existing in L. dugesii populations was due to intrapopulation variation. Only a negligible amount of variation was attributed to differences among populations within and among archipelagos. These values confirm the analysis of variance done on heterozygosity estimates.

Multidimensional Scaling (MDS) plot based on Cavalli-Sforza and Edwards chord distances (Fig. 2, left), shows a close proximity of the Desertas group (DE1, DE2, DE3) to the MA3 population from Madeira Island and to a lesser extent with the other populations from the same island (MA1 and MA2). The two samples from the Selvagens (SE1 and SE2) and the sample from Porto Santo (PS) Island appear to be slightly separated from the others. Although one may be tempted to cluster the populations according to their geographic origin, the truth is that they do not show clear and separate groups. Only the two Selvagens remain close to each other as well DE3, DE1 and MA3. The fact is that the plot from Figure 2, left, allows any kind of interpretation. To assess the effects of geographical distance on genetic divergence in $L$. dugesii populations, pairwise $F S T$-values were tested for correlation with geographic distances. No significant correlation was found $(r=0.47, t=2.9, P>0.05)$. Finally, the multidimensional scaling (MDS) plot based on the Bischoff morphological characters gave different results from those obtained with the enzymatic data (Fig. 2, right). 
Table I. Nei estimates of heterozygosity and gene diversity parameters, per locus, over all populations of Lacerta dugesii and over all loci.

\begin{tabular}{lcccccc}
\hline Loci & $H s$ & $H t$ & $G S T$ & $G I S$ & $\begin{array}{c}\text { GD }^{(\text {a) }} \\
P \text {-values }\end{array}$ & $\begin{array}{c}\text { HW ws } \\
P \text {-values }\end{array}$ \\
\hline ADH & 0.11 & 0.14 & 0.23 & 0.37 & $*$ & NS \\
G3PDH & 0.28 & 0.33 & 0.15 & 0.15 & $*$ & NS \\
EST & 0.29 & 0.36 & 0.21 & 0.26 & $*$ & $*$ \\
AAT & 0.32 & 0.36 & 0.11 & -0.00 & $*$ & NS \\
G6PDH & 0.18 & 0.18 & 0.01 & 0.14 & NS & NS \\
IDH & 0.17 & 0.19 & 0.12 & 0.31 & $*$ & $*$ \\
LAP & 0.04 & 0.05 & 0.11 & -0.13 & $*$ & NS \\
LDH-1 & 0.10 & 0.11 & 0.03 & 0.25 & NS & NS \\
LDH-2 & 0.14 & 0.16 & 0.08 & -0.09 & $*$ & NS \\
MDH & 0.38 & 0.59 & 0.38 & 0.59 & $*$ & $*$ \\
ME-1 & 0.14 & 0.14 & 0.03 & 0.25 & NS & NS \\
ME-3 & 0.35 & 0.46 & 0.27 & 0.37 & $*$ & $*$ \\
PEP-1 & 0.19 & 0.21 & 0.09 & 0.15 & $*$ & NS \\
PEP-2 & 0.08 & 0.09 & 0.02 & 0.27 & NS & $*$ \\
PEP-3 & 0.25 & 0.34 & 0.26 & 0.37 & $*$ & $*$ \\
PEP-4 & 0.10 & 0.11 & 0.09 & 0.36 & $*$ & $*$ \\
PGM-1 & 0.07 & 0.09 & 0.31 & -0.47 & $*$ & NS \\
PGM-2 & 0.03 & 0.03 & 0.00 & 0.01 & NS & NS \\
XDH & 0.03 & 0.04 & 0.02 & -0.03 & NS & NS \\
MPI & 0.08 & 0.09 & 0.08 & 0.11 & $*$ & NS \\
Mean & 0.17 & 0.20 & 0.19 & 0.27 & $*$ & $*$ \\
\hline$* P-$ & & & & & & \\
\hline
\end{tabular}

$* P=0.0025, \mathrm{NS}:$ non-significant;

(a) Test for genotypic differentiation of populations using $G$-tests with 1000 randomisations [13];

(b) $P$-values for testing Hardy-Weinberg within samples.

Table II. Genotypic differentiation parameters within three archipelagos, across loci and populations of Lacerta dugesii.

\begin{tabular}{lcccccc}
\hline Archipelago & $H s$ & $H t$ & $G S T$ & $G I S$ & HW $^{(a)}$ & $N m$ \\
\hline Madeira & 0.15 & 0.18 & $0.19^{*}$ & 0.26 & $*$ & 1 \\
Desertas & 0.19 & 0.20 & $0.09^{*}$ & 0.18 & $*$ & 2 \\
Selvagens & 0.14 & 0.15 & $0.03^{*}$ & 0.28 & $*$ & 4 \\
\hline
\end{tabular}

$* P<0.05, \alpha=0.0025$;

(a) Significance of Hardy-Weinberg tests within samples based on FIS-values, with 1000 randomisations. 
Table III. Hierarchical AMOVA results based on genotype frequencies of Lacerta dugesii populations.

\begin{tabular}{lcccc}
\hline Source of variation & $D f$ & Sum of squares & Percentage of variation & FST \\
\hline Among groups & 3 & 7.15 & 0.11 & $0.0023^{*}$ \\
Among populations, & & & & \\
within groups & 5 & 6.59 & 0.19 & \\
Within populations & 8311 & 4056.5 & 99.70 & \\
\hline
\end{tabular}

$* P<0.0001$.
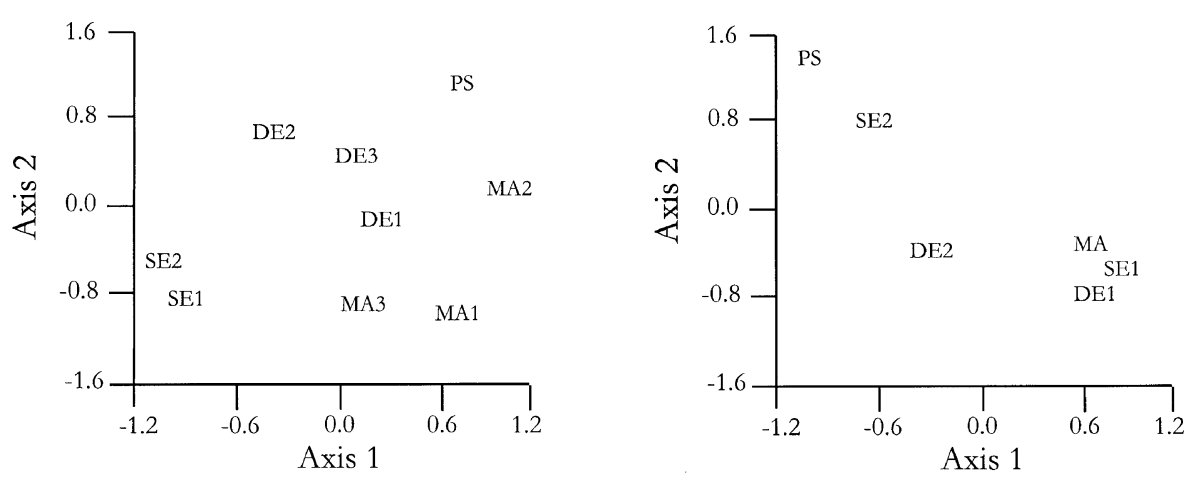

Figure 2. Left: Multidimensional Scaling (MDS) based on Cavalli-Sforza and Edwards [6] chord distance, among populations of Lacerta dugesii plotted in two dimensions. Right: MDS plot based on morphological data published by Bischoff et al. [4].

\section{DISCUSSION AND CONCLUSIONS}

The expected heterozygosity values of $L$. dugesii $(H=0.13)$ averaged over populations was higher than those previously reported for lizard island populations but similar or even higher than those reported for mainland populations [5, $7,11,14,20]$. Podarcis muralis and P. oxycephala from the islets of Lake Skadar have higher heterozygosity values relative to mainland populations [11]. However, populations of Lacerta melisellensis in the Adriatic islands have lower heterozygosity values in more remote islands than in mainland populations, a fact attributed to recent isolation of the islands [15]. Heterozygosity values of Lacerta dugesii populations suggest that none had been subjected to a strong genetic bottleneck. This is supported by the fact that the highest value obtained (0.223) refer to a small island from the Desertas group. Of course, one cannot rule out the possibility that migrations exist among the islands. The high polymorphism level and the GST-values found for each archipelago could easily be transformed into $N m>1$, thus suggesting that gene flow is 
actually taking place. The lack of fixed allele differences among populations also supports a recent colonization by $L$. dugesii although it is impossible to infer the time of colonization of each island from these data. Moreover the most likely explanation for the heterozygote deficiencies found is to admit that populations are structured on a microspatial scale, in other words, a Wahlund effect.

The different $G S T$-values for each locus among populations is a good indicator that selection may be acting differently on some loci or, as Taylor et al. [31] pointed out, gene flow is sufficiently strong to homogenize unselected loci. The data do not suggest that the amount of gene flow is the same among populations; this is not surprising given the different distances separating the various groups of islands. The lowest value of $\mathrm{Nm}$ is found among the three populations from Madeira Island, which are submitted to more diversified environmental conditions, ultimately more efficiently favouring their isolation.

Population pairwise tests for genotype differentiation either on Madeira Island or between populations on different islands reject the null hypothesis of no genotypic differentiation. The AMOVA indicates that most of the genetic variation of $L$. dugesii is found within populations, with much less variation found among populations. Apparently, isolation by distance and oceanic barriers has not lead to effective isolation and differentiation. The significant overall GST-value of 0.19 suggests that some genetic structure exists, with the $G S T$-value for groups of populations being high in Madeira Island and low in the Selvagens. It is population MA2 that contributes most to the differentiation among the Madeira island populations, while the two populations from Selvagens were not differentiated from each other $(G S T=0.03)$.

Lacerta dugesii populations appear genetically distinct from each other but do not show a clear pattern of genetic structuring compatible with their geographic locations, as seen in the MDS plot based on the electrophoretic data. The plot shows that the three samples from Desertas and sample MA3 from Madeira are relatively close which is not surprising, since Madeira Island and the Desertas were certainly linked during the last glaciation periods around $18000 \mathrm{BP}$, and population MA3 inhabits an environment similar to the Desertas. On the small Desertas Islands, the three populations are genetically similar whereas they do not cluster together morphologically. This suggests that selection may be operating even in small areas on apparently similar environmental conditions. Conversely, the three samples from Madeira Island appear to be more different from one another than do samples from different islands. For example, MA2 has been reported as having low lizard density with no gene flow [3]. In fact, lizards in this region exist in high-density groups separated by long distances. This area is environmentally very different from MA1 and MA3, and its lizard population presents marked allelic differences from the other two. The fact that MA2 does not appear close to the other two from the 
same island in the plot of Figure 2, left, could indicate that some of the loci are under strong selection.

The overall week correlation between genetic and geographic distances indicates that genetic divergence among the islands is neither a function nor the result of isolation by distance. In fact, our data suggest that $L$. dugesii populations have a relatively recent dispersion history. Slatkin's [28] model of rapid colonization or population expansion, where a single ancestral population gives rise to extant populations, could explain the observed pattern of genetic divergence in L. dugesii, a case where the isolation-by-distance effect would not be apparent if the "radiations" were recent.

A major conclusion is that the electrophoretic and morphological data reveal different clustering of populations that could be explained by rapid morphological adaptation to different habitats involving drastic changes in morphology but not necessarily in allele frequencies. Others have reported similar findings on lizards inhabiting ecologically different habitats [23,32] and in sticklebacks [25]. Our hypothesis to explain the morphological clustering of populations from different islands is that there is convergence of some characters in similar environments, a fact already found in other lizard populations [19]. Although there is some gene flow among the nine populations of $L$. dugesii, it is not sufficient to override the morphological differences observed, which may be driven by ecological selection and adaptation to the particular environments prevailing in each habitat. Overall, our data point to a weak phylogeographical structure of $L$. dugesii populations, which is not in agreement with the morphological classification of these populations as subspecies.

\section{ACKNOWLEDGEMENTS}

We thank the Parque Natural da Madeira for providing many of the specimens used, Christian Biémont, Jean David and Paul Chippindale for critical comments on the manuscript. José Jesus was a recipient of a post-graduate scholarship from Fundação para a Ciência e Tecnologia, program PRAXIS XXI. Part of this research was supported by JNICT contract PBIC/P/CEN/1096/92 to Luis Vicente. The Centre of Biological and Geological Sciences is supported by Fundação para a Ciência e Tecnologia through program PRAXIS XXI.

\section{REFERENCES}

[1] Arnold E., Towards a phylogeny and biogeography of the Lacertidae: relationships within an old-world family of lizards derived from morphology, Bull. Br. Mus. Nat. Hist. (Zool.) 55 (1989) 209-257. 
[2] Baez M., Observaciones de colorido y diseño de Podarcis dugesii en la isla de Madeira (Sauria, Lacertidae), Vieraea 18 (1990) 197-203.

[3] Baez M., Brown R., Testing multivariate patterns of within-island differentiation in Podarcis dugesii from Madeira, J. Evol. Biol. 10 (1997) 575-587.

[4] Bischoff W., Osenegg K., Mayer W., Untersuchungen zur subspezifischen Gliederung der Madeira-Mauereidechse, Podarcis dugesii (Milne-Edwards, 1829), Salamandra 25 (1989) 237-259.

[5] Bobyn M., Darevsky I., Kupriyanova L., MacCulloch R., Upton D., Danielyan F., Murphy R., Allozyme variation in populations of Lacerta raddei and Lacerta nairensis (Sauria: Lacertidae) from Armenia, Amphibia-Reptilia 17 (1996) 233246.

[6] Cavalli-Sforza L., Edwards A., Phylogenetic analysis: models and estimation procedures, Evol. 21 (1967) 550-570.

[7] Cirer A., Guillaume C., Electrophoretic analysis of the Pityusic islands lizard, in: Rocek Z. (Ed.), Studies in Herpetology, Prague, 1996.

[8] Cockerham C., Weir B., Estimation of gene flow from $F$-statistics, Evol. 47 (1993) 855-863.

[9] Cook L.M., Variation in the Madeira lizard Lacerta dugesii, J. Zool. (Lond.) 187 (1979) 327-340.

[10] Crisp M., Cook L., Hereward F., Color and heat balance in the lizard Lacerta dugesii, Copeia 2 (1979) 250-258.

[11] Crnobrnja-Isailovic J., Dzukic G., Aleksic I, Vujicic L., Avramov S., Podarcis muralis and Lacerta oxycephala (Reptilia: Lacertidae) on the islands of Skadar Lake: Distribution and genetic relationships of populations, in: Llorente G., Montori A., Santos X., Carretero M.A. (Eds.), Scientia Herpetologica, Associación Herpetológica Española, Barcelona, 1995, pp. 71-80.

[12] Excoffier L., Smouse P.E., Quattro J.M., Analysis of molecular variance inferred from metric distances among haplotypes: Application to human mitochondrial DNA restriction data, Genet. 131 (1992) 479-491.

[13] Goudet, J., FSTAT v.1.2: A computer program to calculate $F$-statistics, J. Hered. 86 (1995) 485-486.

[14] Gorman G., Soule M., Yang S., Nevo E., Evolutionary genetics of insular adriatic lizards, Evol. 29 (1975) 52-71.

[15] Gorman G., Buth D., Soule M., Yang S., The relationships of the Anolis cristatellus species group: electrophoretic analysis, J. Herpet. 14 (1980) 269-278.

[16] Guo S.W., Thompson E.A., Performing the exact test of Hardy-Weinberg proportions for multiple alleles, Biometrics 48 (1992) 361-372.

[17] Harris D.J., Arnold E.N., Thomas, R.H., Relationships of lacertid lizards (Reptilia: Lacertidae) estimated from mitochondrial DNA sequences and morphology, Proc. Roy. Soc. London Ser. B 265 (1998) 1939-1948.

[18] Lessa E., Multidimensional analysis of geographic genetic structure, Syst. Zool. 39 (1990) 242-252.

[19] Losos J.B., Jackman T.R., Larson A., Queiroz K., Rodríguez-Schettino L., Contingency and determinism in replicated adaptative radiations of island lizards, Science 279 (1998) 2115-2118.

[20] MacCulloch R., Fu J., Darevsky I., Danielyan F., Murphy R., Allozyme variation in three closely related species of Caucasian rock lizards (Lacerta), AmphibiaReptilia 16 (1995) 331-340. 
[21] Murphy R., Sites J., Buth D., Haufler C., Proteins I: Isozyme electrophoresis, in: Hillis D., Moritz C. (Eds.), Molecular Systematics, Sinauer Associates, Sunderland, MA, 1990, pp. 45-126.

[22] Nei M., F-statistics and analysis of gene diversity in subdivided populations, Ann. Hum. Genet. 41 (1977) 225-233.

[23] Orr M., Smith TH., Ecology and Speciation, TREE 13 (1998) 502-506.

[24] Raymond M., Rousset F., GENEPOP (v.1.2): a population genetics software for exact test and ecuniscism, J. Hered. 95 (1995) 248-249.

[25] Rundle H., Nagel L., Baughman J., Schluter D., Natural selection and parallel speciation in sympatric sticklebacks, Science 287 (2000) 306-308.

[26] Rohlf F., NTSYS-pc: Numerical Taxonomy and Multivariate Analysis System, Exeter Software, New York, 1990.

[27] Schneider S., Kueffer J-M., Roessli D., Excoffier L., Arlequin ver. 1.1: A software for population genetic data analysis, Genetics and Biometry Laboratory, University of Geneva, 1997.

[28] Slatkin M., Isolation by distance in equilibrium and non-equilibrium populations, Evol. 47 (1993) 264-279.

[29] Slatkin M., Maddison, W., Detecting isolation by distance using phylogenies of genes, Genet. 117 (1990) 149-153.

[30] Sokal R.R., Jacquez G.M., Wooten M.C., Spatial autocorrelation analysis of migration and selection, Genet. 121 (1989) 845-855.

[31] Taylor M.F., Shen Y., Kreitman M.E., A population genetic test of selection at the molecular level, Science 270 (1995) 1497-1499.

[32] Vitt L., Caldwell J., Zani P., Titus T., The role of habitat shift in the evolution of lizard morphology: Evidence from tropical Tropidurus, Proc. Nat. Acad. Sci. U.S.A. 94 (1997) 3828-3832.

[33] Weir B., Cockerham C., Estimating F-statistics for the analysis of population structure, Evol. 38 (1984) 1358-1370.

[34] Wright S., The genetical structure of populations, Ann. Eugen. 15 (1951) 323354.

[35] Wright S., Evolution and Genetics of Populations, Vol. 4: Variability within and among Natural Populations, UCP, Chicago, 1978. 


\section{APPENDIX}

Table IV. Allele frequencies per locus, in Lacerta dugesii populations. $N$, is the number of individuals sampled. Codes of populations are as in Figure 1. (continued on next pages)

\begin{tabular}{|c|c|c|c|c|c|c|c|c|c|}
\hline \multirow[t]{2}{*}{ Loci } & \multicolumn{9}{|c|}{ Populations } \\
\hline & SE1 & SE2 & MA1 & MA2 & MA3 & PS & DE1 & DE2 & DE3 \\
\hline \multicolumn{10}{|l|}{ 1.ADH } \\
\hline$(N)$ & 20 & 19 & 24 & 18 & 15 & 24 & 23 & 14 & 24 \\
\hline 1 & 0.97 & 1.0 & 1.0 & 0.69 & 1.0 & 1.0 & 0.67 & 1.0 & 0.98 \\
\hline 2 & 0.02 & 0.00 & 0.00 & 0.30 & 0.00 & 0.00 & 0.33 & 0.00 & 0.02 \\
\hline \multicolumn{10}{|l|}{ 2.G3PDH } \\
\hline$(N)$ & 18 & 17 & 50 & 18 & 15 & 24 & 50 & 14 & 24 \\
\hline 1 & 0.78 & 0.76 & 0.96 & 0.64 & 1.0 & 0.58 & 0.87 & 1.0 & 0.63 \\
\hline 2 & 0.11 & 0.12 & 0.04 & 0.36 & 0.00 & 0.42 & 0.13 & 0.00 & 0.37 \\
\hline 3 & 0.11 & 0.12 & 0.00 & 0.00 & 0.00 & 0.00 & 0.00 & 0.00 & 0.00 \\
\hline \multicolumn{10}{|l|}{ 3.EST } \\
\hline$(N)$ & 20 & 19 & 24 & 18 & 20 & 24 & 24 & 14 & 24 \\
\hline 1 & 0.93 & 0.87 & 0.98 & 0.94 & 1.0 & 0.81 & 0.65 & 0.36 & 0.48 \\
\hline 2 & 0.06 & 0.13 & 0.02 & 0.03 & 0.00 & 0.17 & 0.35 & 0.43 & 0.29 \\
\hline 3 & 0.00 & 0.00 & 0.00 & 0.03 & 0.00 & 0.02 & 0.00 & 0.00 & 0.00 \\
\hline 4 & 0.00 & 0.00 & 0.00 & 0.00 & 0.00 & 0.00 & 0.00 & 0.21 & 0.23 \\
\hline \multicolumn{10}{|l|}{ 4.AAT } \\
\hline$(N)$ & 20 & 17 & 24 & 18 & 15 & 24 & 23 & 14 & 15 \\
\hline 1 & 0.67 & 0.62 & 1.0 & 0.72 & 0.93 & 0.71 & 0.59 & 0.82 & 0.93 \\
\hline 2 & 0.10 & 0.35 & 0.00 & 0.28 & 0.07 & 0.29 & 0.41 & 0.18 & 0.07 \\
\hline 3 & 0.23 & 0.03 & 0.00 & 0.00 & 0.00 & 0.00 & 0.00 & 0.00 & 0.00 \\
\hline \multicolumn{10}{|l|}{ 5.G6PDH } \\
\hline$(N)$ & 20 & 19 & 24 & 18 & 20 & 24 & 24 & 14 & 24 \\
\hline 1 & 0.92 & 0.84 & 0.94 & 0.92 & 0.90 & 0.96 & 0.83 & 0.89 & 0.92 \\
\hline 2 & 0.03 & 0.00 & 0.06 & 0.08 & 0.10 & 0.04 & 0.17 & 0.11 & 0.08 \\
\hline 3 & 0.05 & 0.16 & 0.00 & 0.00 & 0.00 & 0.00 & 0.00 & 0.00 & 0.00 \\
\hline \multicolumn{10}{|l|}{ 6.IDH } \\
\hline$(N)$ & 20 & 19 & 24 & 13 & 15 & 24 & 24 & 14 & 24 \\
\hline 1 & 0.90 & 0.87 & 0.60 & 1.0 & 1.0 & 0.98 & 0.92 & 0.93 & 0.87 \\
\hline 2 & 0.10 & 0.13 & 0.40 & 0.00 & 0.00 & 0.02 & 0.08 & 0.07 & 0.13 \\
\hline \multicolumn{10}{|l|}{ 7.LAP } \\
\hline$(N)$ & 24 & 26 & 26 & 28 & 24 & 24 & 26 & 10 & 7 \\
\hline 1 & 1.0 & 1.0 & 1.0 & 1.0 & 1.0 & 0.83 & 1.0 & 0.95 & 1.0 \\
\hline 2 & 0.00 & 0.00 & 0.00 & 0.00 & 0.00 & 0.17 & 0.00 & 0.05 & 0.00 \\
\hline \multicolumn{10}{|l|}{ 8.LDH-1 } \\
\hline$(N)$ & 20 & 19 & 24 & 18 & 20 & 24 & 23 & 14 & 24 \\
\hline 1 & 1.0 & 0.95 & 1.0 & 0.97 & 0.95 & 0.85 & 0.91 & 0.86 & 1.0 \\
\hline 2 & 0.00 & 0.05 & 0.00 & 0.03 & 0.05 & 0.15 & 0.09 & 0.14 & 0.00 \\
\hline
\end{tabular}


Table IV. continued.

\begin{tabular}{|c|c|c|c|c|c|c|c|c|c|}
\hline \multirow[t]{2}{*}{ Loci } & \multicolumn{9}{|c|}{ Populations } \\
\hline & SE1 & SE2 & MA1 & MA2 & MA3 & PS & DE1 & DE2 & DE3 \\
\hline \multicolumn{10}{|l|}{ 9.LDH-2 } \\
\hline$(N)$ & 20 & 19 & 24 & 18 & 20 & 24 & 24 & 14 & 25 \\
\hline 1 & 1.0 & 0.79 & 0.96 & 0.92 & 1.0 & 1.0 & 0.96 & 0.82 & 0.80 \\
\hline 2 & 0.00 & 0.21 & 0.04 & 0.08 & 0.00 & 0.00 & 0.00 & 0.18 & 0.18 \\
\hline 3 & 0.00 & 0.00 & 0.00 & 0.00 & 0.00 & 0.00 & 0.04 & 0.00 & 0.02 \\
\hline \multicolumn{10}{|l|}{ 10.MDH } \\
\hline$(N)$ & 26 & 26 & 32 & 41 & 35 & 24 & 26 & 9 & 6 \\
\hline 1 & 0.86 & 0.96 & 0.22 & 0.00 & 0.38 & 0.00 & 0.38 & 0.22 & 0.17 \\
\hline 2 & 0.04 & 0.00 & 0.37 & 0.00 & 0.00 & 0.00 & 0.00 & 0.00 & 0.00 \\
\hline 3 & 0.00 & 0.04 & 0.41 & 0.91 & 0.56 & 0.67 & 0.62 & 0.78 & 0.83 \\
\hline 4 & 0.10 & 0.00 & 0.00 & 0.00 & 0.06 & 0.04 & 0.00 & 0.00 & 0.00 \\
\hline 5 & 0.00 & 0.00 & 0.00 & 0.09 & 0.00 & 0.12 & 0.00 & 0.00 & 0.00 \\
\hline 6 & 0.00 & 0.00 & 0.00 & 0.00 & 0.00 & 0.17 & 0.00 & 0.00 & 0.00 \\
\hline \multicolumn{10}{|l|}{ 11.ME-1 } \\
\hline$(N)$ & 26 & 26 & 40 & 47 & 38 & 24 & 26 & 9 & 8 \\
\hline 1 & 0.98 & 0.94 & 0.99 & 0.95 & 0.87 & 0.98 & 0.88 & 0.94 & 0.81 \\
\hline 2 & 0.02 & 0.06 & 0.00 & 0.02 & 0.08 & 0.02 & 0.06 & 0.06 & 0.00 \\
\hline 3 & 0.00 & 0.00 & 0.01 & 0.03 & 0.05 & 0.00 & 0.06 & 0.00 & 0.19 \\
\hline \multicolumn{10}{|l|}{ 12.ME-3 } \\
\hline$(N)$ & 46 & 46 & 38 & 65 & 52 & 48 & 50 & 14 & 24 \\
\hline 1 & 0.40 & 0.36 & 0.80 & 0.93 & 0.34 & 0.87 & 0.60 & 0.93 & 0.92 \\
\hline 2 & 0.59 & 0.64 & 0.13 & 0.01 & 0.53 & 0.07 & 0.33 & 0.00 & 0.08 \\
\hline 3 & 0.01 & 0.00 & 0.07 & 0.06 & 0.13 & 0.06 & 0.07 & 0.07 & 0.00 \\
\hline \multicolumn{10}{|l|}{ 13.PEP-1 } \\
\hline$(N)$ & 23 & 26 & 64 & 47 & 35 & 24 & 26 & 8 & 7 \\
\hline 1 & 0.96 & 1.0 & 0.72 & 0.94 & 0.90 & 0.83 & 0.69 & 0.94 & 1.0 \\
\hline 2 & 0.00 & 0.00 & 0.16 & 0.00 & 0.01 & 0.13 & 0.04 & 0.00 & 0.00 \\
\hline 3 & 0.04 & 0.00 & 0.12 & 0.06 & 0.09 & 0.00 & 0.27 & 0.06 & 0.00 \\
\hline 4 & 0.00 & 0.00 & 0.00 & 0.00 & 0.00 & 0.04 & 0.00 & 0.00 & 0.00 \\
\hline \multicolumn{10}{|l|}{ 14.PEP-2 } \\
\hline$(N)$ & 20 & 26 & 34 & 42 & 38 & 24 & 26 & 9 & 8 \\
\hline 1 & 0.98 & 0.94 & 0.90 & 1.0 & 0.91 & 1.0 & 0.89 & 1.0 & 1.0 \\
\hline 2 & 0.02 & 0.06 & 0.06 & 0.00 & 0.00 & 0.00 & 0.02 & 0.00 & 0.00 \\
\hline 3 & 0.00 & 0.00 & 0.04 & 0.00 & 0.09 & 0.00 & 0.09 & 0.00 & 0.00 \\
\hline \multicolumn{10}{|l|}{ 15.PEP-3 } \\
\hline$(N)$ & 42 & 42 & 64 & 65 & 38 & 23 & 50 & 14 & 18 \\
\hline 1 & 0.76 & 0.97 & 0.96 & 0.82 & 0.91 & 0.24 & 0.87 & 0.93 & 0.67 \\
\hline 2 & 0.00 & 0.00 & 0.00 & 0.01 & 0.03 & 0.00 & 0.02 & 0.00 & 0.00 \\
\hline 3 & 0.24 & 0.03 & 0.04 & 0.17 & 0.06 & 0.67 & 0.11 & 0.07 & 0.33 \\
\hline 4 & 0.00 & 0.00 & 0.00 & 0.00 & 0.00 & 0.09 & 0.00 & 0.00 & 0.00 \\
\hline
\end{tabular}


Table IV. continued.

\begin{tabular}{|c|c|c|c|c|c|c|c|c|c|}
\hline \multirow[t]{2}{*}{ Loci } & \multicolumn{9}{|c|}{ Populations } \\
\hline & SE1 & SE2 & MA1 & MA2 & MA3 & PS & DE1 & DE2 & DE3 \\
\hline \multicolumn{10}{|l|}{ 16.PEP-4 } \\
\hline$(N)$ & 25 & 26 & 36 & 42 & 38 & 24 & 26 & 9 & 8 \\
\hline 1 & 0.96 & 1.0 & 0.82 & 0.99 & 0.77 & 0.94 & 1.0 & 1.0 & 1.0 \\
\hline 2 & 0.04 & 0.00 & 0.11 & 0.00 & 0.21 & 0.00 & 0.00 & 0.00 & 0.00 \\
\hline 3 & 0.00 & 0.00 & 0.07 & 0.01 & 0.02 & 0.06 & 0.00 & 0.00 & 0.00 \\
\hline \multicolumn{10}{|l|}{ 17.PGM-1 } \\
\hline$(N)$ & 24 & 26 & 26 & 28 & 24 & 24 & 26 & 10 & 7 \\
\hline 1 & 1.0 & 1.0 & 0.98 & 0.63 & 1.0 & 1.0 & 0.96 & 1.0 & 1.0 \\
\hline 2 & 0.00 & 0.00 & 0.02 & 0.37 & 0.00 & 0.00 & 0.00 & 0.00 & 0.00 \\
\hline 3 & 0.00 & 0.00 & 0.00 & 0.00 & 0.00 & 0.00 & 0.04 & 0.00 & 0.00 \\
\hline \multicolumn{10}{|l|}{ 18.PGM-2 } \\
\hline$(N)$ & 23 & 26 & 26 & 28 & 24 & 24 & 26 & 10 & 7 \\
\hline 1 & 1.0 & 1.0 & 0.96 & 0.98 & 1.0 & 1.0 & 0.98 & 0.95 & 1.0 \\
\hline 2 & 0.00 & 0.00 & 0.04 & 0.02 & 0.00 & 0.00 & 0.00 & 0.00 & 0.00 \\
\hline 3 & 0.00 & 0.00 & 0.00 & 0.00 & 0.00 & 0.00 & 0.02 & 0.05 & 0.00 \\
\hline \multicolumn{10}{|l|}{ 19.XDH } \\
\hline$(N)$ & 20 & 19 & 24 & 18 & 15 & 24 & 24 & 14 & 24 \\
\hline 1 & 1.0 & 1.0 & 0.96 & 0.94 & 1.0 & 0.94 & 1.0 & 1.0 & 1.0 \\
\hline 2 & 0.00 & 0.00 & 0.04 & 0.06 & 0.00 & 0.06 & 0.00 & 0.00 & 0.00 \\
\hline \multicolumn{10}{|l|}{ 20.MPI } \\
\hline$(N)$ & 20 & 19 & 24 & 18 & 16 & 24 & 22 & 14 & 16 \\
\hline 1 & 0.97 & 1.0 & 0.96 & 1.0 & 0.97 & 1.0 & 0.78 & 0.96 & 0.94 \\
\hline 2 & 0.03 & 0.00 & 0.04 & 0.00 & 0.03 & 0.00 & 0.22 & 0.04 & 0.06 \\
\hline \multicolumn{10}{|c|}{ Mean of number of alleles } \\
\hline & 2.0 & 1.7 & 2.0 & 2.0 & 1.9 & 2.0 & 2.1 & 1.8 & 1.7 \\
\hline \multicolumn{10}{|c|}{ Percentage of polymorphic loci } \\
\hline & 0.70 & 0.60 & 0.80 & 0.80 & 0.55 & 0.70 & 0.85 & 0.70 & 0.60 \\
\hline \multicolumn{10}{|c|}{ Mean of observed heterozygosity $(H)$} \\
\hline & 0.108 & 0.098 & 0.102 & 0.142 & 0.094 & 0.135 & 0.223 & 0.115 & 0.133 \\
\hline (ST. error) & $(0.031)$ & $(0.030)$ & $(0.025)$ & $(0.040)$ & $(0.024)$ & $(0.038)$ & $(0.043)$ & $(0.030)$ & $(0.038)$ \\
\hline \multicolumn{10}{|c|}{ Expected Heterozygosity } \\
\hline & 0.141 & 0.145 & 0.157 & 0.163 & 0.137 & 0.187 & 0.246 & 0.151 & 0.169 \\
\hline (ST. error) & $(0.038)$ & $(0.038)$ & $(0.042)$ & $(0.037)$ & $(0.040)$ & $(0.042)$ & $(0.041)$ & $(0.037)$ & $(0.044)$ \\
\hline $\mathrm{HWE}^{\text {(a) }}$ & * & $*$ & * & NS & $*$ & $*$ & * & NS & NS \\
\hline $\begin{array}{l}\text { estimates } \\
\text { FIS }^{(b)}\end{array}$ & $*$ & $*$ & $*$ & NS & $*$ & $*$ & NS & $*$ & NS \\
\hline
\end{tabular}

Adenylate kinase (AK) 2.7.4.3; Alcohol Dehydrogenase (ADH) 1.1.1.1; Aspartate aminotransferase (AAT) 2.6.1.1; Esterase (EST) 3.1.1.-; Glucose-6-phosphate Dehydrogenase (G6PDH) 1.1.1.49; Glycerol-3-phosphate Dehydrogenase (G3PDH) 1.1.1.8; Isocitrate Dehydrogenase (IDH) 1.1.1.42; L-Lactate Dehydrogenase (LDH-1, LDH-2) 1.1.1.27; Leucine Aminopeptidase (LAP) 3.4.11.-; Malate Dehydrogenase NAD (MDH) 1.1.1.37; Malate Dehydrogenase NADP (ME-1, ME-2) 1.1.1.40; Manose-6-phosphate Isomerase (MPI) 5.3.1.8; Peptidase (PEP-1, PEP-3) 3.4.-.-; Peptidase (PEP-2, PEP-4) 3.4.-.-; Phosphoglucose Isomerase (PGI) 5.3.1.9; Phosphoglucomutase (PGM - 1, PGM-2) 5.4.2.2; Superoxide Dismutase (SOD) 1.15.1.1; Xanthine Dehydrogenase (XDH) 1.1.1.204. $* P<0.0025$; (a) Unbiased estimate of $P$-values using the Markov chain method; (b) $P$-values of $F P$ within samples, with 1000 randomisations. 